\title{
HUBUNGAN STANDARISASI DAN INVENTARISASI TERHADAP KINERJA KARYAWAN HOTEL
}

\author{
Livia Oeynardi ${ }^{1}$, Lexi Pranata B. Limbing ${ }^{2 *}$ \\ ${ }^{1,2}$ Program Studi Pariwisata, Fakultas Pariwisata, Universitas Ciputra Surabaya \\ Jl. Citraland CBD Boulevard, Citraland Surabaya, Indonesia \\ Email: ${ }^{1}$ oeynardi@gmail.com; ${ }^{2}$ limbing@ciputra.ac.id \\ *Penulis korespondensi
}

\begin{abstract}
Abstrak
Tujuan dari penelitian ini yaitu untuk menganalisis dan menguji pengaruh antar Standarisasi dan Inventarisasi Terhadap Kinerja Karyawan Hotel. Jenis penelitian yang digunakan penelitian kuantitatif. Populasi yang diterapkan pada penelitian ini adalah seluruh karyawan departemen food and beverage Service di Hotel Aria Centra Surabaya. Sampel yang diteliti adalah 23 responden yang terdiri dari 1 orang Manajer, satu orang Supervisor, dua orang Leader, tujuh orang Daily Worker dan 12 orang Trainee. Teknik yang digunakan dalam penelitian ini yaitu analisis regresi linier berganda. Pengujian data yang digunakan adalah uji validitas, uji reliabilitas, uji asumsi klasik, dan uji hipotesis. Hasil diolah menggunakan software SPSS 23 yang akan digunakan untuk memperoleh kesimpulan berdasarkan data yang diperoleh. Berdasarkan hasil penelitian yang kemudian dianalisis maka dapat diambil kesimpulan bahwa Standarisasi berpengaruh secara signifikan terhadap kinerja karyawan. Hasil uji simultan menggunakan uji F antara Standarisasi dan Inventarisasi berpengaruh secara simultan terhadap Kinerja Karyawan. Sedangkan variabel Inventarisasi tidak berpengaruh secara signifikan terhadap kinerja karyawan. Oleh sebab itu, untuk penelitian selanjutnya yang menggunakan variabel yang sama disarankan untuk mempertimbangkan kembali faktor-faktor lain yang mempengaruhi seperti menambahkan jumlah responden dan variabel lainnya agar penelitian akan menjadi lebih baik.
\end{abstract}

Kata kunci: Standarisasi, Inventariasi, Kinerja Karyawan.

\begin{abstract}
The purpose of this research is to analyse and test the influence between standardization and inventory against Hotel employee performance. Types of research used quantitative research. The population applied to this study is all employees of the food and beverage Service Department at Hotel Aria Centra Surabaya. The samples examined were 23 respondents consisting of one manager, one person Supervisor, two leaders, seven Daily workers and 12 trainees. The technique used in this study is a double linear regression analysis. The data tests used are validity tests, reliability tests, classical assumption tests, and hypotheses testing. Results are processed using SPSS 23 software that will be used to derive conclusions based on the data obtained. Based on the results of the research then analyzed it can be concluded that standardization significantly affects the performance of employees. Simultaneous test results using the F Test between standardization and inventory influence simultaneously on employee performance. While the inventory variables do not significantly affect the performance of employees. Therefore, for subsequent studies using the same variables it is advisable to reconsider other factors that affect such as adding the number of respondents and other variables so that the research will be better.
\end{abstract}

Keywords: Standardization, Inventory, Employee Performance.

\section{ENDAHULUAN}

Dalam dunia perhotelan hal yang sangat diperhatikan setiap hotel yaitu pelayanannya. Karena pelayanan merupakan salah satu kunci keberhasilan dalam membangun bisnis perhotelan seperti menurut (Tjiptono, 2004) Perusahaan harus mulai memikirkan pentingnya pelayanan pelanggan secara lebih matang melalui kualitas pelayanan, karena pelayan merupakan aspek vital dalam mempertahankan bisnis dan memenangkan persaingan. Kualitas pelayanan yang baik tentunya diberikan melalui kinerja karyawan hotel yang memuaskan. Kinerja karyawan dapat diberikan dengan baik kepada tamu karena setiap karyawan sudah memiliki standar kerja dalam pelayanan.

Standard Operational Procedure merupakan sebuah standar akan suatu aturan khusus, prinsip atau tindakan yang ditetapkan sebagai acuan untuk 
karyawan dalam menjalankan tugas secara konsisten (Kotschevar \& Luciani, 2007). Hal ini dilakukan agar setiap tamu mendapatkan pelayanan yang sama satu dengan yang lainnya. Standarisasi akan selalu dipertahankan guna meningkatkan kinerja karyawan dalam memberikan pelayanan. Dalam melakukan pekerjaan sesuai dengan standar maka karyawan akan menawarkan barang yang tersedia dalam pengolahan makanan atau minuman. Maka dari itu, persediaan barang yang lengkap akan membantu dalam melakukan standard operational procedure (SOP) yang sudah ada.

Persediaan barang atau inventarisasi seringkali diabaikan oleh karyawan hotel dan memperhatikan kelengkapan dalam inventarisasi tidak mudah. Hal ini dikarenakan setiap harinya barang yang diperlukan tidaksama dan barang yang dipakai dan yang tersedia tidak selalu sama, tergantung permintaan dari tamu. Persediaan menurut (Ramadhani, 2018; Rudianto, 2013) merupakan suatu istilah yang menunjukan segala sesuatu dari sumber daya yang ada dalam satu proses dengan tujuan untuk mengantisipasi terhadap segala kemungkinan yang terjadi baik karena adanya permintaan maupun masalah lain. Maka dari itu seharusnya inventarisasi yang benar akan mempengaruhi standarisasi terhadap kinerja karyawan.

Penelitian ini diangkat berdasarkan pengalaman penulis pada saat magang. Pada saat magang di Hotel Aria Centra Surabaya selama enam bulan banyak hal yang diperhatikan oleh penulis. Penulis memperhatikan kinerja karyawan yang kurang efektif dikarenakan standar setiap karyawan berbeda. Selain itu ketersediaan barang yang terkadang jarang diperhatikan menyebabkan karyawan bekerja terlihat kurang profesional di depan tamu. Sedangkan jika standarisasi diterapkan dengan baik maka akan memudahkan dalam inventarisasi barang yang juga berdampak pada keefektifan kinerja karyawan. Berdasarkan pemaparan diatas maka peneliti tertarik untuk mengadakan penelitian dengan judul "Hubungan Standarisasi dan Inventarisasi Dalam Kinerja Karyawan Hotel"

\section{TINJAUAN PUSTAKA}

\section{Standarisasi}

Merupakan suatu aturan khusus, prinsip atau tindakan yang ditetapkan sebagai acuan untuk karyawan dalam menjalankan tugas secara konsisten (Kotschevar \& Luciani, 2007). Menurut (Sundbo, 2002) Standarisasi adalah cara untuk mengurangi biaya, secara bersamaan juga dapat meningkatkan produktivitas dan harga yang lebih rendah.
Produktivitas meningkat yang bagus di perusahaan jasa jika mereka menggunakan standarisasi yang baik (Sundbo, 1994). Aspek Standarisasi Menurut (Padma, 2004) hotel memiliki beberapa tipe Standarisasi antaranya Tool Procedure, Rule Procedure, Job Procedure. Indikator Standarisasi menurut (Putrianti, 2010) hal mendasar untuk menjadi atau mencapai standar pramusaji profesional antara lain:

1. Personal Hygiene, standar kebersihan seorang pelayan harus diperhatikan karena pelayan yang langsung bertemu dengan tamu dan menangani makanan dan minuman tamu. Selain itu pelayan juga tidak diperbolehkan batuk atau bersendawa di depan tamu atau pada saat berdekatan dengan tamu.

2. Knowledge of Food and Beverage, sebagai seorang pelayan harus memiliki pengetahuan tentang makanan dan minuman yang dijual. Hal ini akan sangat berpengaruh pada saat mengarahkan tamu untuk membeli. Selain itu pelayan juga harus mengerti lebih tentang bahan yang digunakan pada makanan dan minuman agar tidak salah dalam mengarahkan tamu sesuai keinginan dan kebutuhan tamu

3. Punctuality, disiplin waktu merupakan salah satu cara menunjukan kinerja yang baik pelayan. Jika pelayan tepat waktu maka juga memiliki rasa hormat kepada manajemen dan hal ini akan berpengaruh baik kedepannya baik secara langsung atau pun tidak langsung pada proses pelayanan.

4. Pengetahuan Lokal, sebagai pelayan pengetahuan akan keadaan daerah bekerja merupakan hal yang penting. Hal ini akan berpengaruh pada saat memberikan informasi arahan kepada tamu yang hendak berlibur atau melakukan perjalan bisnis. Pengetahuan ini akan memberikan nilai kepuasan terhadap tamu

5. Personality, kepribadian seorang pelayan diharapkan dapat berbaur dengan tamu agar dapat membangun suasana atau atmosfer yang nyaman bagi tamu. Memiliki kepribadian merupakan atribut yang bisa meningkatkan menjadi manajemen yang baik.

6. Sikap Terhadap Tamu, pendekatan yang tepat terhadap tamu merupakan hal yang harus diperhatikan guna memaksimalkan interaksi pada proses pelayanan. Jika terdapat complaint pramusaji juga harus menyikapi dengan berkoordinasi terdahulu dengan atasan yang masuk pada hari itu.

7. Daya Ingat, daya ingat merupakan aset utama dalam melayani. Jika seorang pelayan mengingat hal tentang tamu maka akan menjadi nilai lebih dan 
akan mempermudah pelayanan dalam berinteraksi dan tamu.

8. Kejujuran, merupakan presentasi dari perusahaan yang menjadi pihak ketiga dan tentunya hubungan baik antara pelayan, perusahaan dan tamu harus dijaga dengan baik. Hal ini dapat dicapai dengan kejujuran, selain itu kejujuran juga mampu dalam menciptakan suasana kerja yang baik dan dapat meningkatkan rasa semangat dalam kebersamaan dalam menjalankan operasional.

\section{Inventarisasi}

Inventori merupakan bahan baku, barang jadi, barang yang diproses, barang yang sudah tersedia yang dimiliki perusahaan dalam tempat penyimpanan atau dikonsinyasikan kepada pihak lain pada akhir periode menurut (Ramadhani, 2018; Kohler, 2007). Selain itu Menurut (Prasetyo, 2006) persediaan atau inventarisasi merupakan suatu aktiva, yang meliputi barang milik perusahaan dengan tujuan untuk dijual dalam satu periode usaha yang normal, termasuk juga barang yang lagi dikerjakan/ proses produksi hanya menunggu masa penggunaanya pada proses produksi. Aspek Inventarisasi menurut (Dwiantara, 2009) merupaka barang-barang perbekalan yang dilakukan pada saat inventarisasi terdiri dari 2 jenis antaranya barang habispakai dan barang tetap. Indikator pelaksanaan Inventarisasi yang sesuai dengan SOP menurut (Wedyanto, 2014), yaitu:

1. Tercatat penambahan aset yang tepat

2. Terinventorisasinya aset yang baik

3. Tersusunnya daftar inventaris ruangan yang akurat

4. Penomoran barang yang dilakukan secara cepat tidak lebih dari 30 hari kalender setelah neraca ditutup

\section{Kinerja Karyawan}

Kinerja karyawan menurut (Sabir, et al., 2012) merupakan elemen yang sangat penting disetiap organisasi dan merupakan faktor yang paling penting dalam keberhasilan berorganisasi untuk mencapai hasil yang memuaskan atau maksimal. Aspek Kinerja Karyawan menurut (Wirawan, 2009) terdapat tiga faktor yang mempengaruhi kinerja seorang karyawan adalah faktor lingkungan internal, faktor lingkungan eksternal organisasi dan faktor internal karyawan. Indikator penilaian Kinerja Karyawan Menurut (Robbins, 2006) ada enam indikator kinerja karyawan, antara lain kualitas, kuantitas, ketepatan waktu, efektivitas, kemandirian, komitmen kerja

\section{Model Penelitian}

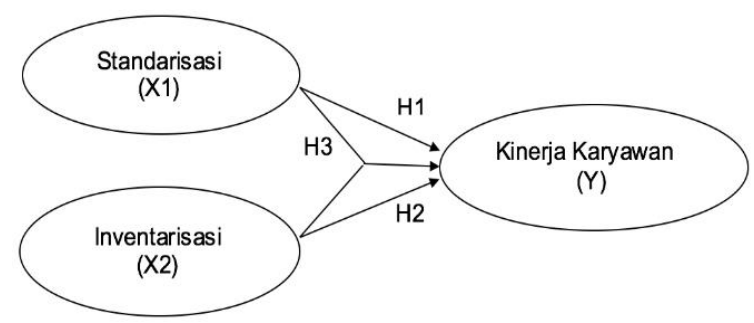

Gambar 1. Model Penelitian

\section{Hipotesis}

Berdasarkan hasil penelitian, maka penelitian hubungan standarisasi dan inventarisasi terhadap kinerja karyawan, penulis merumuskan hipotesis antara lain:

H1: Diduga terdapat hubungan antara Standarisasi terhadap kinerja karyawan

H2: Diduga terdapat hubungan antara Inventarisasi terhadap kinerja karyawan

H3: Diduga terdapat pengaruh standarisasi dan inventarisasi terhadap kinerja karyawan

\section{METODE PENELITIAN}

\section{Rancangan Penelitian, Gambaran Populasi dan Sampel Penelitian}

Penelitian ini menggunakan pendekatan kuantitatif metode deskriptif. Penulis melakukan survei terhadap seluruh karyawan departemen Food and Beverages Service di Hotel Aria Centra untuk mendapatkan informasi dan data yang dikumpulkan dan diolah secara statistik deskriptif melalui teknik penyebaran kuesioner dalam menganalisa mengenai hubungan standarisasi dan inventarisasi terhadap kinerja karyawan. Penulis menggunakan populasi homogen, yang diambil adalah seluruh karyawan departemen Food and Beverages Service. Dengan menggunakan teknik penarikan sampel Nonprobability Sampling jenis sampel jenuh. Sampel penelitian yang digunakan berupa keseluruhan dari populasi yang ada yaitu seluruh karyawan dari departemen Food and Beverages Service dengan jumlah 23 responden.

\section{Variabel dan Definisi Operational Variabel Standarisasi}

Aturan khusus dalam menjalankan pekerjaan secara konsisten. Indikator Empirik oleh (Putrianti, 2010), antara lain: 
a. Personal Hygiene, Perhatian lebih terhadap standar kebersihan sebagai pelayan

b. Knowledge of Food and Beverage, Pengetahuan tentang makanan dan minuman

c. Punctuality, Tepat waktu dalam bekerja

d. Pengetahuan Lokal, Paham mengenai pengetahuan local

e. Personality, Memiliki sikap yang ramah dan cekatan

f. Sikap Terhadap Tamu, Peduli dan memperhatikan keinginan tamu

g. Daya Ingat, Daya ingat terhadap pesanan tamu

h. Kejujuran, Kejujuran dalam bekerja

\section{Inventarisasi}

Suatu aktiva barang milik perusahaan dengan tujuan untuk dijual dan diolah. Indikator Empirik oleh (Wedyanto, 2014), antara lain:

a. Tercatat penambahan aset yang tepat, Pencatatan yang tepat pada saat penambahan barang

b. Terinventorisasinya aset yang baik, Barang keluar masuk tercatat rapi

c. Tersusunnya daftar inventaris ruangan yang akurat, Daftar inventaris ruangan tersusun dengan akurat

d. Penomoran barang yang dilakukan secara cepat tidak lebih dari 30 hari kalender setelah neraca ditutup, Penomoran barang dilakukan dengan cepat

\section{Kinerja Karyawan}

Faktor yang paling penting dalam keberhasilan berorganisasi untuk mencapai hasil yang memuaskan atau maksimal. Indikator Empirik Sumber oleh (Robbins, 2006), antara lain:

a. Kualitas, Terampil dan kemampuan

b. Kuantitas, Melakukan banyak pekerjaan

c. Ketepatan waktu, Bekerja tepat waktu

d. Efektivitas, Bekerja efektivitas

e. Kemandirian, Mandiri dalam bekerja

f. Komitmen kerja, Berkomitmen dan tanggung jawa

\section{ANALISA DAN PEMBAHASAN}

\section{Analisis Deskriptif}

Penelitian ini melibatkan pegawai dari food and beverages service di Hotel Aria Centra Surabaya. Dengan jumlah 23 Orang dengan laki-laki sebanyak $56,5 \%$, sedangkan perempuan sebanyak 43.5\% (10 orang karyawan). Dengan jabatan $4.3 \%$ yang menjabat sebagai manajer, $4.3 \%$ dengan jabatan supervisor,
$8.7 \%$ dengan jabatan sebagai leader, $21.7 \%$ jabatan sebagai daily worker dan sebanyak $52.2 \%$ sebagai trainee di Hotel Aria department food and beverages service.

\section{Teknik Analisa Data}

Variabel Standarisasi direfleksikan oleh 8 indikator dengan tingkat reliabilitas yang tinggi (Cronbach's Alpha $=0.982)$ dan disetiap indikator memiliki nilai signifikan pada uji validitas yaitu 0,000 . Nilai deviasi terendah pada variabel Standarisasi adalah indikator "Sikap Terhadap Tamu" yaitu 0.822 . Hasil tersebut dapat menunjukan akan adanya keberagaman data penelitian.

Variabel Inventarisasi dicerminkan oleh 4 indikator dengan tingkat reliabilitas sebesar 0.961 (Cronbach's Alpha) dan disetiap indikator memiliki nilai signifikan pada uji validitas yaitu 0,000 dibawah 0,05 . Nilai deviasi pada indikator inventarisasi nilai terendah yaitu 0.834 pada indikator "Tercatat penambahan aset yang tepat". Maka hasil tersebut dapat menunjukan adanya keberagaman data penelitian.

Variabel Kinerja Karyawan direfleksikan oleh 6 indikator dengan tingkat reliabilitas sebesar 0.891 (Cronbach's Alpha) dan disetiap indikator memiliki nilai signifikan pada uji validitas yaitu 0,000 dibawah 0,05. Nilai deviasi pada indikator kinerja karyawan nilai terendah yaitu 0.843 pada indikator "Kemandirian", Maka hasil tersebut dapat menunjukan adanya keberagaman data penelitian.

\section{Analisa Regresi Linier Berganda}

Analisis regresi linear berganda dilakukan dalam penelitian ini guna mengetahui hubungan antara Standarisasi dan Inventarisasi terhadap Kinerja Karyawan di departemen food and beverage service di Hotel Aria Centra Surabaya. Rumus dalam regresi linear berganda yaitu ' $\mathrm{Y}$ ' $=\beta_{0}+\beta_{1} \mathrm{X}_{1}+\beta_{2} \mathrm{X}_{2}$ "'. Berikut adalah hasil regresi linier berganda penelitian ini:

Tabel 1. Regresi Linier Berganda

\begin{tabular}{|c|c|c|c|c|c|c|}
\hline \multirow{2}{*}{\multicolumn{2}{|c|}{ Model }} & \multicolumn{2}{|c|}{ Unstandardized Coefficients } & \multirow{2}{*}{$\begin{array}{c}\begin{array}{c}\text { Standardized } \\
\text { Coefficients }\end{array} \\
\text { Beta }\end{array}$} & \multirow[b]{2}{*}{$\mathrm{t}$} & \multirow[b]{2}{*}{ Sig. } \\
\hline & & B & Std. Error & & & \\
\hline \multirow[t]{3}{*}{1} & (Constant) & 3.666 & 1.523 & & 2.407 & .026 \\
\hline & sumX2 & .327 & .211 & .259 & 1.547 & .137 \\
\hline & sum $\times 1$ & .401 & .098 & .686 & 4.102 & .001 \\
\hline
\end{tabular}

. Dependent Variable: sumY1

Kinerja Karyawan $=3.666+0.401$ Standarisasi + 0.327 Inventarisasi 
Berdasarkan data diatas Nilai konstan 3.666 merupakan konstanta yang memiliki arti besarnya nilai Kinerja Karyawan, jika Standarisasi dan Inventarisasi adalah 0 maka masih terdapat Kinerja Karyawan sebesar 3.666 maka Kinerja Karyawan adalah konstan.

\section{Koefisien Korelasi (R) dan Koefisien Determinasi $\left(\mathbf{R}^{2}\right)$}

Tabel 2. Koefisien Korelasi dan Koefisien Determinasi

\begin{tabular}{|l|c|r|r|r|r|}
\hline Model & R & R Square & $\begin{array}{c}\text { Adjusted R } \\
\text { Square }\end{array}$ & $\begin{array}{l}\text { Std. Error of } \\
\text { the Estimate }\end{array}$ & $\begin{array}{c}\text { Durbin- } \\
\text { Watson }\end{array}$ \\
\hline 1 & $.915^{\text {a }}$ & .838 & .821 & 1.96944 & 2.433 \\
\hline
\end{tabular}
a. Predictors: (Constant), sumX1, sumX2
b. Dependent Variable: sumY1

Hasil koefisien korelasi (R) yang diperoleh adalah sebesar 0.915 dan nilai koefisien determinasi $\left(\mathrm{R}^{2}\right)$ sebesar 0.838 . Nilai koefisien korelasi (R) sebesar 0.915 menunjukan bahwa variabel independen yaitu Standarisasi dan Inventarisasi memiliki hubungan yang sangat kuat dengan Kinerja Karyawan departemen food and beverage service di Hotel Aria Centra Surabaya. Selain itu hasil dari nilai koefisien determinasi $\left(\mathrm{R}^{2}\right)$ sebesar 0.838 yang menunjukan bahwa variabel Standarisasi dan Inventarisasi di Hotel Aria Centra Surabaya memiliki hubungan dengan Kinerja Karyawan departemen food and beverage service sebesar $83,8 \%$ dan sisanya $16.2 \%$ berhubungan oleh variabel lain yang tidak termasuk dalam penelitian ini.

\section{Uji Hipotesis}

\section{Pengaruh Simultan (Uji F)}

Berikut data untuk hasil uji $\mathrm{F}$ regresi atau uji pengaruh simultan dalam penelitian ini, sebagai berikut:

Tabel 3. Hasil Uji F

\begin{tabular}{|c|c|c|c|c|c|c|}
\hline \multicolumn{7}{|c|}{ ANOVA $^{\mathrm{a}}$} \\
\hline & & $\begin{array}{l}\text { Sum of } \\
\text { Squares }\end{array}$ & df & Mean Square & $\mathrm{F}$ & Sig. \\
\hline \multirow{3}{*}{$\frac{M c}{1}$} & Regression & 400.079 & 2 & 200.039 & 51.574 & $.000^{6}$ \\
\hline & Residual & 77.574 & 20 & 3.879 & & \\
\hline & Total & 477.652 & 22 & & & \\
\hline
\end{tabular}

Berdasarkan hasil nilai $\mathrm{F}$ yang dihitung sebanyak 51.574 dengan nilai signifikansi sebesar 0.000 yang nilainya kurang dari 0.05 atau $\alpha=5 \%$. Maka dapat disimpulkan bahwa Standarisasi dan Inventarisasi simultan berpengaruh signifikan terhadap Kinerja
Karyawan pada departemen food and beverage service di Hotel Aria Centra Surabaya.

\section{Pengaruh Parsial (Uji t)}

Berdasarkan tabel 1 sebelumnya, pengujian antar standarisasi terhadap kinerja karyawan menghasilkan t hitung sebesar 4.102 dengan nilai signifikan sebesar dari 0.001 . Dengan nilai signifikan yang kurang dari $0.05(\alpha=5 \%)$ dan $\mathrm{H} 0$ ditolak tetapi $\mathrm{H} 1$ diterima. Maka dengan demikian dapat disimpulkan bahwa variabel independen (standarisasi) terhadap Kinerja Karyawan berpengaruh signifikan.

Nilai t hitung yang dihasilkan pengujian hubungan Inventarisasi terhadap kinerja karyawan sebesar 1.547 dengan nilai signifikan sebesar 0.137 . Nilai signifikan lebih dari $0.05(\alpha=5 \%)$ dan $\mathrm{H} 0$ diterima tetapi $\mathrm{H} 1$ ditolak sehingga dapat disimpulkan bahwa Inventarisasi tidak berpengaruh signifikan terhadap kinerja karyawan departemen food and beverage service di Hotel Aria Centra.

\section{Uji Asumsi Klasik}

1. Uji Normalitas

Uji normalitas memiliki tujuan yaitu untuk menguji residual pada model regresi untuk melihat apakah berdistribusi normal atau tidak. Pengujian menggunakan uji Kolmogorov-Smirnov dimana jika nilai signifikan uji Kolmogorov-Smirnov lebih besar dari $0.05(\alpha=5 \%)$ maka dikatakan normal. Pada hasil menunjukan bahwa nilai signifikansi uji Kolmogorov-Smirnov sebesar 0.200, dimana nilai tersebut lebih besar dari 0.05 sehingga dapat disimpulkan bahwa residual pada model regresi berdistribusi normal.

2. Uji Multikolinieritas

Uji multikolinieritas memiliki tujuan untuk mencari tahu ada tidaknya korelasi antar variabel bebas dalam model regresi. Agar dapat mengetahuinya dapat melihat pada nial VIF (Variance Inflation Factor) dimana apabila nilai lebih besar dari 10 maka terjadi multikolinearitas dan sebaliknya apabila nilai lebih kecil dari 10 maka model regresi bebas dari multikolinearitas. Berdasarkan hasil dapat diketahui bahwa nilai VIF (Variance Inflation Factor) adalah 3.448 pada masing-masing variable bebas dibawah 10 . Maka dari itu nilai ini dapat menjelaskan bahwa model regresi bebas dari multikolinearitas.

3. Uji Heteroskedasitas

Model regresi yang baik tidak menimbulkan adanya gejala heteroskedastisitas. Pengujian menggunakan uji Gletser yang memiliki tujuan untuk 
meregresikan antara variabel bebas dengan absolut residual model regresi. Nilai signifikansi yaitu 0.05 ( $\alpha=5 \%$ ) maka dapat dinyatakan tidak terjadi gejala heteroskedastisitas. Pada penelitian bahwa nilai signifikansi untuk variabel standarisasi sebesar 0.200 dan untuk variabel inventarisasi sebesar 0.549. Kedua nilai dari setiap variabel diatas 0.05 sehingga dapat dikatakan bahwa asumsi tidak ada heteroskedastisitas dalam model regresi penelitian ini terbukti kebenarannya.

4. Uji Autokorelasi

Pengujian ini bertujuan untuk mencari tahu terjadi tidaknya korelasi antar residual pengamatan. Dalam pengujian ini menggunakan Durbin Watson (DW). non autokorelasi dikatakan terpenuhi jika nilai DW yang dihasilkan terletak diantara nilai dU sampai nilai 4-dU. Pada penelitian nilai DW dari hasil regresi adalah sebesar 2.433 dimana nilai tersebut berada diantara nilai batas atas yakni 1.543 dan nilai 4 kurang nilai batas atas yaitu 2.457. Nilai $\mathrm{dU}$ sendiri didapat dari tabel dimana $\mathrm{n}$ adalah jumlah responden dan $\mathrm{k}$ adalah jumlah dari variabel bebas dalam penelitian ini. Maka dari itu dapat disimpulkan, bahwa tidak terdapat autokorelasi pada model regresi.

5. Uji Linieritas

Uji Linieritas dilakukan untuk mencari tahu ada atau tidak adanya hubungan secara linier masingmasing pada variabel bebas dengan variabel terikat dengan melalui Test of Linearity dengan nilai signifikansi hasilnya dibawah $0.05 \quad(\alpha=5 \%)$ maka dapat disimpulkan bahwa variabel terikat dan variabel bebas memiliki hubungan linear. Pada penelitian diketahui bahwa kedua nilai signifikansi F melalui Test of Linearity menghasilkan nilai signifikan kurang dari 0.05 yaitu 0,000. Maka dapat disimpulkan hubungan antara dua variabel yaitu Standarisasi (F Linearity=112.729) dan Inventarisasi (F Linearity=76.136) dinyatakan masing-masing terdapat hubungan linier dengan variabel Kinerja Karyawan departemen food and beverage service di Hotel Aria Centra Surabaya.

\section{Pengaruh Standarisasi Terhadap Kinerja Karyawan}

Pada hipotesis pertama dalam penelitian ini adalah terdapat dugaan hubungan positif secara parsial dan signifikan antara Standarisasi terhadap Kinerja Karyawan pada departemen food and beverage service di Hotel Aria Centra Surabaya. Dugaan tersebut terbukti kebenarannya melalui nilai signifikan uji $\mathrm{t}$ 0.001 dan nilai koefisien regresi positif senilai 0.401 terhadap variabel Kinerja Karyawan. Hal ini sejalan dengan penelitian terdahulu yang dilakukan oleh
(Wardani, 2018) yang menggunakan analisis nilai berganda yang mana mengukur standar operasional terhadap kinerja karyawan hotel di Everbright hotel yaitu dengan nilai signifikan 0.03 dimana hasil lebih kecil dari 0.05 .

\section{Pengaruh Inventarisasi Terhadap Kinerja Karyawan}

Pada hipotesis kedua dalam penelitian ini adalah terdapat dugaan hubungan positif secara parsial dan signifikan antara Inventarisasi terhadap Kinerja Karyawan pada departemen food and beverage service di Hotel Aria Centra Surabaya. Dugaan tersebut terbukti akan tidak kebenarannya melalui nilai signifikan uji t 0.137. Dengan perolehan persamaan model regresi linier berganda yang diketahui bahwa variabel Inventarisasi menunjukan nilai 0.327 terhadap variabel Kinerja Karyawan. Keadaan Inventarisasi di Hotel Aria Centra Surabaya pada saat ini terkadang masih kurang terperhatikan dengan baik, tetapi dengan adanya beberapa bahan yang masih dapat digantikan fungsinya dapat membuat kinerja karyawan masih dapat berjalan dengan baik. Hal ini didukung dengan adanya hasil penelitian yang dilakukan oleh (Hidayat, 2018) dalam penelitian yang menguji sistem informasi akuntansi penjualan dan persediaan barang terhadap kinerja karyawan yang memiliki hasil yang tidak signifikan yaitu dengan nilai signifikannya 0,312 dimana standarnya yaitu $<0.05$. Dalam penelitian terdahulu disebabkan jumlah responden hanya 34 orang yang mungkin diperlukan penambahan jumlah responden agar penelitian lebih baik dan berpengaruh secara signifikan.

\section{Pengaruh Standarisasi dan Inventarisasi Ter- hadap Kinerja Karyawan}

Pada hipotesis terakhir dalam penelitian ini adalah dugaan adanya hubungan positif secara simultan dan signifikan antara Standarisasi dan Inventarisasi terhadap Kinerja Karyawan departemen food and beverage service di Hotel Aria Centra Surabaya. Dugaan ini terbukti kebenarannya melalui nilai signifikansi uji $\mathrm{F}$ yaitu sebesar 0.000 . Tentunya dugaan ini didukung dengan hasil koefisien determinasi $\left(\mathrm{R}^{2}\right)$ dengan nilai 0.838 atau sebesar $83,8 \%$ terhadap variabel Standarisasi dan Inventarisasi terhadap Kinerja Karyawan.

\section{KESIMPULAN DAN SARAN}

Berdasarkan keseluruhan uraian hasil olah dari data primer dan pembahasan, maka dapat ditarik kesimpulan yaitu, sebagai berikut: 
1. Standarisasi terhadap Kinerja Karyawan departemen food and beverage service di Hotel Aria Centra Surabaya berpengaruh secara parsial sehingga hipotesis pertama dalam penelitian ini diterima kebenarannya.

2. Inventarisasi terhadap Kinerja Karyawan departemen food and beverage service di Hotel Aria Centra Surabaya tidak berpengaruh secara parsial sehingga hipotesis kedua dalam penelitian ini ditolak kebenarannya.

3. Standarisasi dan Inventarisasi terhadap Kinerja Karyawan departemen food and beverage service di Hotel Aria Centra Surabaya berpengaruh secara simultan sehingga hipotesis ketiga dalam penelitian ini diterima kebenarannya.

Berdasarkan kesimpulan dari penelitian dan pembahasan yang telah dilaksanakan, maka saran yang diberikan dalam penelitian ini adalah sebagai berikut:

1. Berdasarkan hasil penelitian ini erat hubungannya dengan karyawan maka dapat digunakan pihak Human Resources Department (HRD) dalam meningkatkan kinerja karyawan terutama pada food and beverage service department di Hotel Aria Centra Surabaya yaitu dengan cara mengajarkan standarisasi pada setiap karyawan dan melakukan pelatihan secara berkala. Hal ini bertujuan sesuai pada latar belakang dalam mendorongnya keberhasilan dalam membangun binsis perhotelan yaitu kualitas pelayanan yang diberikan melalui kinerja karyawan kepada tamu dengan standar yang ada guna menghasilkan kinerja karyawan yang lebih efektif. Selain itu dengan adanya standarisasi dalam bekerja juga akan mempengaruhi kelengkapan inventarisasi dalam bekerja.

2. Penelitian ini juga memiliki tujuan bagi peneliti selanjutnya yang hendak meneliti dengan tema dan judul penelitian yang sama atau serupa. Pada penelitian ini dapat diketahui bahwa hasil dari variabel inventariasi terhadap kinerja karyawan memiliki hasil yang tidak signifikan (uji $\mathrm{t}=0.137$ ). Maka bagi peneliti selanjutnya, disarankan untuk menambahkan variabel lain yang juga memiliki pengaruh terhadap kinerja karyawan. Selain itu jika peneliti selanjutnya terkhusus yang menggunakan variabel inventarisasi disarankan untuk meneliti dengan menggunakan populasi dan sampel yang lebih banyak yaitu ke beberapa divisi tidak hanya pada satu departemen.

\section{DAFTAR REFERENSI}

Dwiantara, L., \& Hadi, R.S. (2009). Manajemen Logistik Pedoman Praktis Bagi Sekretaris dan Staf Administrasi. Jakarta: Grasindo.

Hidayat, N. (2018). Pengaruh Sistem Informasi Akuntansi Penjualan dan Persediaan Barang Dagang Berbasis Client Server Terhadap Kinerja Karyawan Cipto Jaya Sadel Lamongan. 3(1), 672-673

Kotschevar, L.H., \& Luciani, V. (2007). Presenting Service: The Ultimate Guide For the food service professional. New Jersey: John Wiley \& Sons.

Padma, S K. (2004). Industry- A meta analysis and business model on the HR related issues and attitudes. Bangalore: Sindhu Cargo Service Ltd.

Prasetyo, H. (2006). Pengembangan Model Persediaan dengan mempertimbang kan Waktu Kadaluarsa dan Faktor Unit Diskon. 4(3), 14126869

Putrianti, S. (2010). Standar Pelayanan Pramusaji di Deli Coffee Shop Hotel Inna Dharma Deli Medan. Medan: Universitas Sumatera Utara.

Ramadhani, T. (2018). Sistem Informasi Stok Gudang Pada Platinum Hotel Berbasis Web. 6(2), 36.

Robbins, S.P. (2006). Perilaku Organisasi. PT. Indeks Kelompok Gramedia

Sabir, M.S., Iqbal, J.J., Rehman, K.U., Shah, K.A., \& Yameen, M. (2012). Impact of Corporate Ethical Values on Ethical leadership and Employee Performance. Journal of business and social science. 3(2),163-171.

Sundbo, J. (1994). Modulation of Service Production and Thesis of Convergence Between Service and Manufacturing Organizations. 10(22), 245-266.

Sundbo, J. (2002). The Service Economy: Standardisation or Customisation. The Service Industries Journal. 22(4), 93-116.

Tjiptono, F. (2004). Manajemen Jasa. Yogyakarta: Andi Offset. 50(5), 145.

Wardani, Y. (2018). Pengaruh Gaya Kepemimpinan, Standar Operasional Prosedur dan Turn Over Terhadap Kinerja Karyawan Hotel Everbright di Surabaya. 4(3), 16

Wirawan. (2009). Evaluasi Kinerja Sumber Daya Manusia Teori, Aplikasi dan Penelitian. Jakarta: Salemba Empat.

Wedyanto. (2014). Penomoran dan Inventarisasi Aset. Bandung: ITB. 